\title{
Three new species of foetid Gymnopus in New Zealand
}

\author{
Jerry A. Cooper', Pat L. Leonard ${ }^{2}$ \\ I Landcare Research, PO Box 40, Lincoln, 7640, New Zealand 2 Motueka, New Zealand \\ Corresponding author: Jerry Cooper (cooperj@landcareresearch.co.nz)
}

Academic editor: S. Redhead | Received 18 January 2013 | Accepted 24 June 2013 | Published 26 June 2013

Citation: Cooper JA, Leonard PL (2013) Three new species of foetid Gymnopus in New Zealand. MycoKeys 7: 31-44. doi: $10.3897 /$ mycokeys.7.4710

\begin{abstract}
We describe three new species, Gymnopus imbricatus, G. ceraceicola and G. hakaroa, from New Zealand that are similar to G. foetidus (= Micromphale foetidum), growing on wood, with an insititious stipe and foetid odour. The position of these species within the /gymnopoid clade is confirmed by ITS sequence analysis.
\end{abstract}

\section{Key words}

Gymnopus, Micromphale, New Zealand

\section{Introduction}

The new species we describe are members of the family Omphalotaceae Matheney et al. (2006) and have the morphological characteristics of Gymnopus section Vestipedes subsection Impudicae (Antonín \& Noordeloos 2010) which contains Micromphale foetidum (Sowerby) Singer, the type species of the formerly recognised genus Micromphale (e.g. in the sense of Singer 1986). Fruitbodies of the group often have a foetid odour when crushed, described as like rotting cabbage or garlic. The only existing records of this group in New Zealand were found to be misapplications of names applied to northern hemisphere species.

Moncalvo et al. (2002) investigated nLSU rDNA sequence data for a large number of agarics and recognised a /micromphale clade containing M. foetidum (AF261328). The clade also contained Gymnopus pro parte, Caripia, Setulipes and Micromphale. 
Their /micromphale clade was nested within a broader /lentinuloid clade including Rhodocollybia, Marasmiellus ramealis (Bull.) Singer, Marasmius scorodonius (Fr.) Fr. and Lentinula. Mata et al. (2004), based on an LSU analysis, also identified a clade containing sequences of $M$. foetidum and material named as Setulipes androsaceus (L.) Antonín and Gymnopus fusipes (Bull.) Gray, the type species of those respective genera. They adopted a broad concept of Gymnopus incorporating these genera together with Marasmiellus. Wilson and Desjardin (2005) used LSU to examine the group and identified a /gymnopus clade containing G. fusipes, M. foetidum, S. androsaceus at its core with Micromphale perforans (Hoffm.) Gray lying on its boundary. These results were broadly supported by Mata et al. (2006) in their analysis using ITS1-5.8-ITS2 but they demonstrate clustering of G. fusipes, $S$. androsaceus and Micromphale on the periphery of a concentration of Gymnopus-labelled samples. On the basis of these results the currently generally accepted concept of Gymnopus is broad (e.g. Noordeloos 2012), and incorporates a number of previously recognised genera. Hughes et al. (2010) erected the genus Connopus to accommodate the Gymnopus acervatus group within the gymnopoid clade and presented LSU and ITS data indicating its placement close to Rhodocollybia. Their LSU analysis supports a core gymnopoid clade containing G. fusipes, S. androsaceus, which once again places Micromphale foetidum and $M$. perforans on a boundary with a sister group containing Rhodocollybia, Marasmiellus juniperinus Murrill and various Gymnopus species. The /gymnopus, clade as interpreted by Hughes et al., contains significant substructure. A multi-gene analysis including more representatives may indicate the recognition of further segregates at genus-level. In this paper we accept our newly described species within the current broad concept of Gymnopus whilst recognising their close alliance to the historical concept of the genus Micromphale.

For this study we analysed ITS1-5.8-ITS2 data for related New Zealand collections together with representative sequences from Genbank, many from the studies cited above. The structure of our ITS tree is consistent with these previous analyses, and once again identifies a /micromphale clade closely linked to core Gymnopus species. ITS data generated for a number of representative collections of our newly described taxa support species concepts based on morphology.

\section{Materials and methods}

\section{Morphological protocols}

Spore dimensions are stated as the mean \pm 1.5 SD of 20 measurements, thus covering $86 \%$ of measurements under an assumed normal distribution model. Fresh or dried material was examined mounted in $10 \% \mathrm{KOH}$ or Melzer's reagent. Material was handsectioned. Some micrographs were obtained under DIC conditions. Measurements were always taken without DIC optics and an extended objective iris in order to maximise boundary contrast. 


\section{Phylogenetic protocols}

DNA extraction and sequencing followed the protocols outlined in Cooper and Leonard (2012). We downloaded from Genbank selected sequences used in cited publications, together with close BLAST matches, Table 1. General sequence management was carried out using Geneious (Drummond et al. 2011). Data exchange between applications was facilitated using Alter (Glez-Peña et al. 2010). Sequence alignment was carried out using MAFFT within Geneious (Katoh et al. 2002). A maximum likelihood analysis was executed using RAxML (Stamatakis 2006), with 100 bootstrap runs, launched from Topali 2.5 (Milne et al. 2004). The substitution model of GTR+G was recommended by Topali 2.5. We selected a sequence of Anthracophyllum archeri (Berk.) Pegler as the outgroup.

Table I. ITS Sequences used in the analysis. New sequences generated for this analysis are in bold.

\begin{tabular}{|c|c|c|c|c|}
\hline Genbank \# & Collection \# & Organism & PDD Voucher\# & Country \\
\hline DQ444308 & TENN50049 & Anthracophyllum archeri & & New Zealand \\
\hline DQ480112 & TENN58672 & Gymnopus alkalivirens & & Greenland \\
\hline DQ480114 & TENN55834 & Gymnopus alpinus & & Scotland \\
\hline AY256691 & TENN57012 & Gymnopus aquosus & & Germany \\
\hline DQ449971 & TENN59738 & Gymnopus aquosus & & USA \\
\hline KC248409 & PL6304 & Gymnopus ceraceicola & PDD 101750 & New Zealand \\
\hline KC248389 & PL126406 & Gymnopus ceraceicola & PDD 101754 & New Zealand \\
\hline KC248400 & PL189402 & Gymnopus ceraceicola & PDD 76358 & New Zealand \\
\hline KC248403 & JAC9334 & Gymnopus ceraceicola & PDD 80771 & New Zealand \\
\hline KC248405 & JAC10084 & Gymnopus ceraceicola & PDD 87181 & New Zealand \\
\hline KC248404 & JAC10336 & Gymnopus ceraceicola & PDD 87424 & New Zealand \\
\hline KC248394 & JAC10395 & Gymnopus ceraceicola & PDD 87483 & New Zealand \\
\hline KC248408 & JAC10817 & Gymnopus ceraceicola & PDD 87661 & New Zealand \\
\hline KC248392 & RHP13063 & Gymnopus ceraceicola & PDD 90101 & New Zealand \\
\hline KC248391 & KWH12891 & Gymnopus ceraceicola & PDD 90119 & New Zealand \\
\hline KC248393 & RHP12871 & Gymnopus ceraceicola & PDD 90132 & New Zealand \\
\hline KC248397 & JAC11005 & Gymnopus ceraceicola & PDD 95459 & New Zealand \\
\hline KC248395 & JAC11093 & Gymnopus ceraceicola & PDD 95544 & New Zealand \\
\hline AY256690 & TENN57012 & Gymnopus dryophilus & & USA \\
\hline DQ449974 & TENN58087 & Gymnopus dryophilus & & Costa Rica \\
\hline AF505778 & TENN 59141 & Gymnopus dysodes & & Costa Rica \\
\hline AY256694 & TENN59457 & Gymnopus earleae & & USA \\
\hline DQ449973 & TFB10718 & Gymnopus exculptus & & Greenland \\
\hline AF505780 & FB11434 & Gymnopus foetidum & & USA \\
\hline AY256710 & TENN59217 & Gymnopus fusipes & & France \\
\hline KC248407 & JAC9585 & Gymnopus hakaroa & PDD 81086 & New Zealand \\
\hline KC248410 & JAC10225 & Gymnopus hakaroa & PDD 87315 & New Zealand \\
\hline KC248411 & PL25404 & Gymnopus imbricatus & PDD 101753 & New Zealand \\
\hline KC248406 & JAC10089 & Gymnopus imbricatus & PDD 87186 & New Zealand \\
\hline
\end{tabular}




\begin{tabular}{l|l|l|l|l}
\hline Genbank \# & Collection \# & Organism & PDD Voucher\# & Country \\
\hline KC248398 & JAC10310 & Gymnopus imbricatus & PDD 87398 & New Zealand \\
\hline KC248401 & JAC10322 & Gymnopus imbricatus & PDD 87410 & New Zealand \\
\hline KC248399 & JAC10815 & Gymnopus imbricatus & PDD 87659 & New Zealand \\
\hline KC248402 & JAC10816 & Gymnopus imbricatus & PDD 87660 & New Zealand \\
\hline KC248396 & JAC10495 & Gymnopus imbricatus & PDD 87675 & New Zealand \\
\hline KC248390 & JAC11038 & Gymnopus imbricatus & PDD 95489 & New Zealand \\
\hline AF505779 & TENN56658 & Gymnopus impudicus & & Costa Rica \\
\hline DQ449986 & Duke RV94154 & Gymnopus iocephalus & & USA \\
\hline AY256693 & TENN59532 & Gymnopus junquilleus & & USA \\
\hline DQ449960 & TENN50620 & Gymnopus ocior & & Switzerland \\
\hline DQ449972 & TENN56321 & Gymnopus subsulphureus & & USA \\
\hline AY263453 & AWW115 & Gymnopus vitellinipes & & Java/Bali \\
\hline AY256708 & TENN59540 & Marasmiellus juniperinus & & USA \\
\hline GU234007 & JB14 & Marasmius androsaceus & & UK \\
\hline DQ444312 & TENN50482 & Marasmius androsaceus & & USA \\
\hline DQ444311 & TENN50704 & Marasmius androsaceus & & Austria \\
\hline DQ449990 & TENN59293 & Micromphale brassicolens & & \\
\hline & & & & \\
\hline
\end{tabular}

\section{Results}

Our analysis places the New Zealand taxa in a monophyletic clade close to G. foetidum and G. brassicolens historically recognised in the genus Micromphale (Fig. 1). The combination of sequence data and morphological analysis of many collections indicate two major groups which we equate with the newly described species $G$. imbricatus and $G$. ceraceicola. In addition we recognise a further species, G. hakaroa, which is poorly distinguished from $G$. imbricatus on the basis of ITS sequences but which is morphologically consistently different. Minor sequence variation in the G. ceraceicola group does not correlate with morphology and we choose to recognise these specimens as a single species. More information and images of collections may be found on the Landcare Research website (Systematics Collections Data).

\section{Gymnopus ceraceicola J.A. Cooper \& P. Leonard, sp. nov.}

http://species-id.net/wiki/Gymnopus_ceraceicola

Holotype: PDD 87181. Registration identifier: IF550091

Diagnosis. G. ceraceicola is distinguished from related New Zealand species by the combination of pruinose, central stipe and dark pileus.

Macromorphology. Pileus 5-20 mm, generally broadly convex to applanate, but sometimes campanulate when young, brick to purplish chestnut, minutely felty, radially furrowed and striate towards the margin, margin slightly fimbriate. Lamellae cream, creamy yellow to vinaceous buff, waxy, adnate. Lamellae present, in series of 


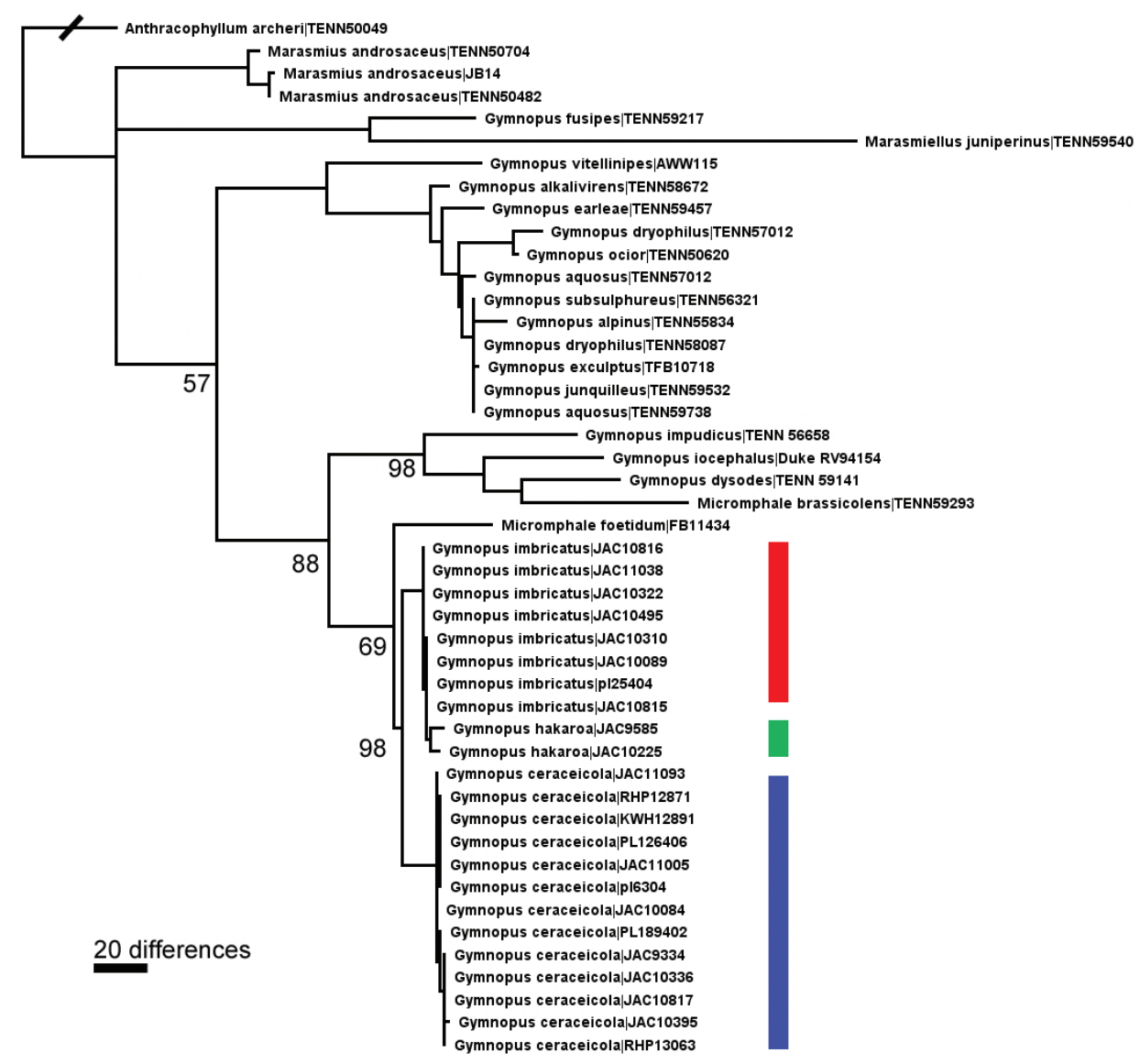

Figure I. Maximum likelihood cladogram of selected ITS sequences, with bootstrap proportion. Red bar = Gymnopus imbricatus, green bar $=$ G. hakaroa, blue bar $=$ G. ceraceicola

three: intercalated short/long/short. Stipe central, cartilaginous, 10-20 × 1-2 mm, equal, brown vinaceous, sometimes paler towards apex or base, always entirely finely pruinose. Stipe base insititious and always associated with a thin waxy to chalky cream layer of partially gelatinised hyphae covering the substrate. This layer is often extensive, with a distinct margin, and often green with algal cells. Fruitbodies with garlic/rotten cabbage smell, especially when crushed.

Micromorphology. Pileipellis a partially gelatinised radially arranged clamped cutis of smooth hyphae to $5 \mu \mathrm{m}$ diameter, with brown extra-cellular encrustation. Epidermal layer to $140 \mu \mathrm{m}$. Subepidermis of thick glassy-walled non-gelatinised smooth hyaline hyphae, weakly dextrinoid. Basidia clavate to $40 \times 8 \mu \mathrm{m}$. Sterigmata to $7 \mu \mathrm{m}$, 4-spored. Basidioles cylindrical, tapering towards apex, $40 \times 4 \mu \mathrm{m}$. Spores hyaline, lacrymoid, $7.9 \pm 1 \times 4.5 \pm 0.6 \mu \mathrm{m}, \mathrm{Q}=1.8 \pm 0.1$ including apiculus. Cheilocystidia and pleurocystidia not observed. Stipitipellis a cutis of brown parallel hyphae, to $5 \mu \mathrm{m}$ wide. Caulocystidia smooth, hyaline, agglutinated into fascicles. 

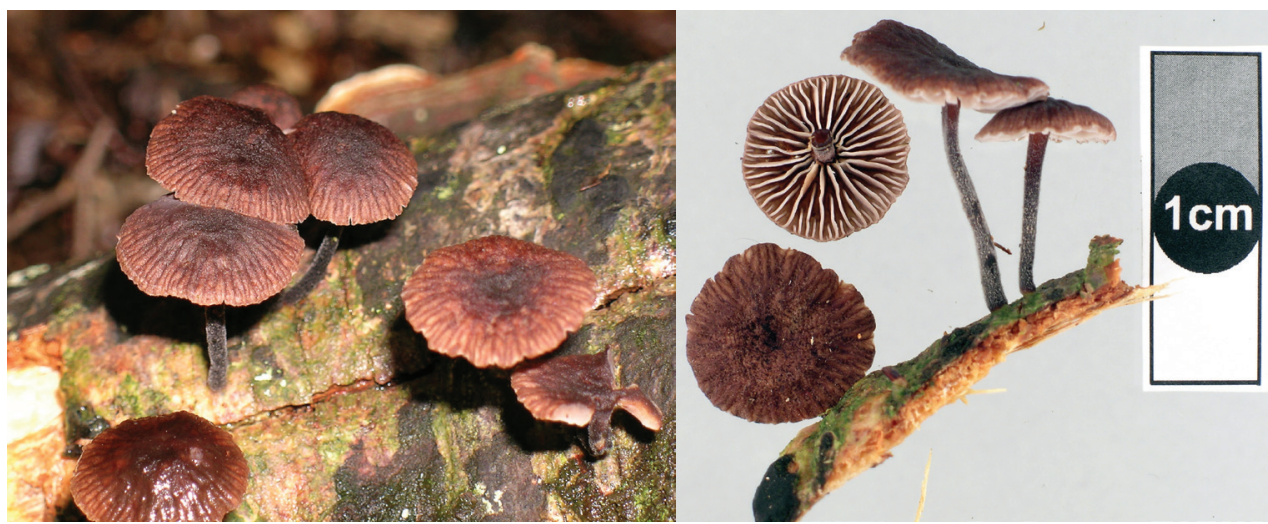

Figure 2. Gymnopus ceraceicola Holotype, PDD 87181. Fruitbodies.

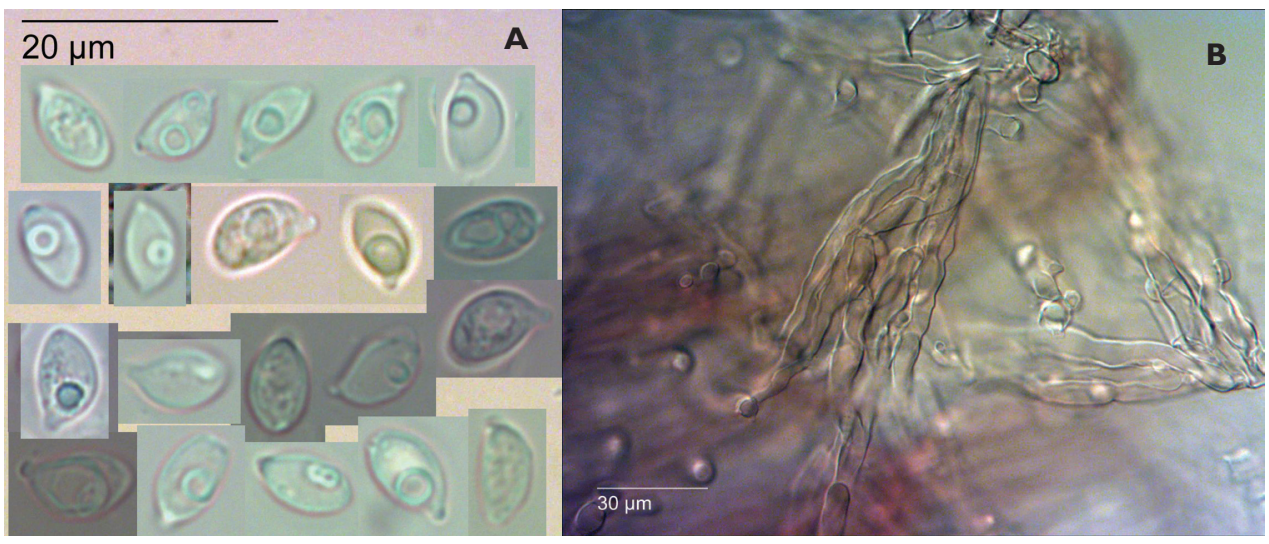

Figure 3. Gymnopus ceraceicola Holotype, PDD 87181. A Spores (KOH) B Agglutinated fascicles of caulocystidia on stipe $(\mathrm{KOH})$.

Habitat. Colonies of a few to hundreds of fruitbodies on bark of fallen, dead branches and twigs, especially Nothofagus.

Distribution. Broadly distributed and common in both North and South Islands of New Zealand.

Etymology. Ceraceicola, indicating association with a basal waxy layer, although this feature is common to the three species described here.

Notes. Sequence data indicate variability in the taxon but the morphological details are constant and we choose to recognise a single species. New Zealand records of Gymnopus (Micromphale) foetidum and Gymnopus (Micromphale) brassicolens are attributable to G. ceraceicola. Authentic New Zealand material of these two species has not been identified. Gymnopus brassicolens has paler pileus colours, non-gelatinized pileipellis, cheilocystidia and pileipellis elements with lateral projections, and larger basidiospores. Gymnopus foetidus is macroscopically similar but does not possess the agglutinate fascicles of caulocystidia of G. ceraceicola. 
Specimens examined. New Zealand, North Island: PDD 40852, on dead wood, Anawhata Rd., Waitakare Ranges, Collector P.R. Johnston \& G. Samuels, 9 June 1981. PDD 80771, on dead wood of Beilschmiedia tawa, Erua Forest, Taupo, Collector J.A. Cooper (JAC9334), 4 April 2005. PDD 87382, on dead wood of Nothofagus fusca, Mt Holdsworth, Gentle Annie Track, Wairarapa, Collector J.A. Cooper (JAC10294), 11 May 2007. PDD 87483, on wood, Mt Holdsworth, Donnelly Flat Loop Track, Wairarapa, Collector G. Gates \& D. Ratkowsky (JAC10395), 7 May 2007. PDD 87424, on dead bark of Nothofagus, Mt Holdsworth, Gentle Annie Track, Wairarapa, Collector J.A. Cooper (JAC10336), 11 May 2007. PDD 95544, on bark of Nothofagus fusca, Rimutaka Forest Park, Wellington, Collector J.A. Cooper (JAC11093), 14 May 2009. PDD 95545, on bark of dead branch of Nothofagus fusca, Rimutaka Forest Park, Wellington, Collector J.A. Cooper (JAC11094), 14 May 2009.

New Zealand, South Island: PDD 76357, on dead twig of Nothofagus, Canaan Road Track, Nelson, Collector P.L. Leonard, 30 April 2002. PDD 96730, on dead wood, Wangapeka, Nelson, collector P.L. Leonard (PL126406), 14 April, 2006. PDD 90101=TENN 061068, on bark, vicinity of Seddonville, Charming Creek Track, Nelson, Collector R.H. Petersen (RHP 13063), 11 May 2006. PDD 76358, on bark on dead branch of Nothofagus menziesii, Lake Daniels Track, Nelson, Collector P.L. Leonard (PL189402), 2 April 2002. PDD 95459, on bark of dead branch of Nothofagus solandri, Kowai Bush, Springfield, Mid Canterbury, Collector J.A. Cooper (JAC11005), 2 May 2009. PDD 95462, on bark of dead branch of Nothofagus solandri, Kowai Bush, Springfield, Mid Canterbury, Collector J.A. Cooper (JAC1 1008), 2 May 2009. Holotype PDD 87181, on dead branch of Nothofagus fusca, Hinewai Reserve, Akaroa, Mid Canterbury, Collector J.A. Cooper (JAC10084), 3 June 2006. PDD 87661, on dead twigs of Leptospermum scoparium, Government Track, Waipori Falls Road, Dunedin, Collector K. Soop (JAC10817), 12 May 2008. PDD 96636, on dead wood of Nothofagus solandri, Lake Hauroko, Fiordland, Collector P. White (JAC12522). 7 May 2012. PDD $90119=$ TENN061007, on twigs, Vicinity of Te Anau, Kepler Track from Rainbow Reach, Fiordland, Collector K.W. Hughes (KWH12891), 30 April 2006. PDD 90132=TENN060986, vicinity Manapouri, Borland Lodge, Nature Track, Fiordland, Collector R.H. Petersen (RHP12871), 29 April 2006.

\section{Gymnopus imbricatus J.A. Cooper \& P. Leonard, sp. nov.}

http://species-id.net/wiki/Gymnopus_imbricatus

Holotype: PDD 95489. Registration identifier: IF550092

Diagnosis. G. imbricatus is distinguished from related New Zealand species by the smooth stipe, larger basidiospores, and imbricate habit.

Macromorphology. Pileus 3-20 mm in diameter convex, cream to fawn, minutely felty, radially furrowed and striate towards the margin, margin fimbriate. Lamellae cream to creamy yellow, adnate. Lamellae present, in series of two: short/long. Stipe mostly eccentric, cartilaginous, to $3 \times 0.5 \mathrm{~mm}$, equal, umber to black, sometimes paler 


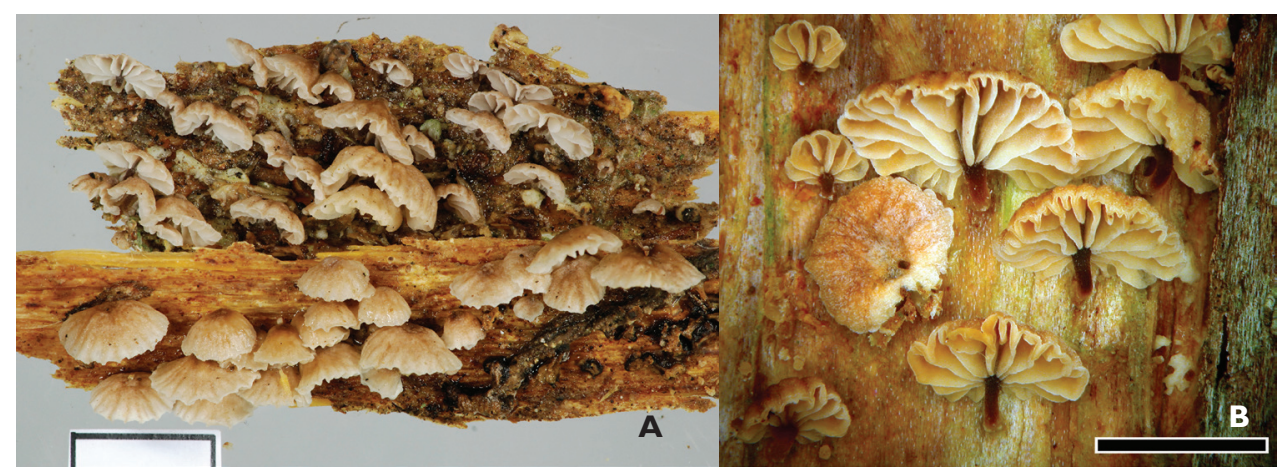

Figure 4. Gymnopus imbricatus. A Holotype PDD 95489. Fruitbodies, scale $1 \mathrm{~cm}$ B PDD 87186. Scale $1 \mathrm{~mm}$.

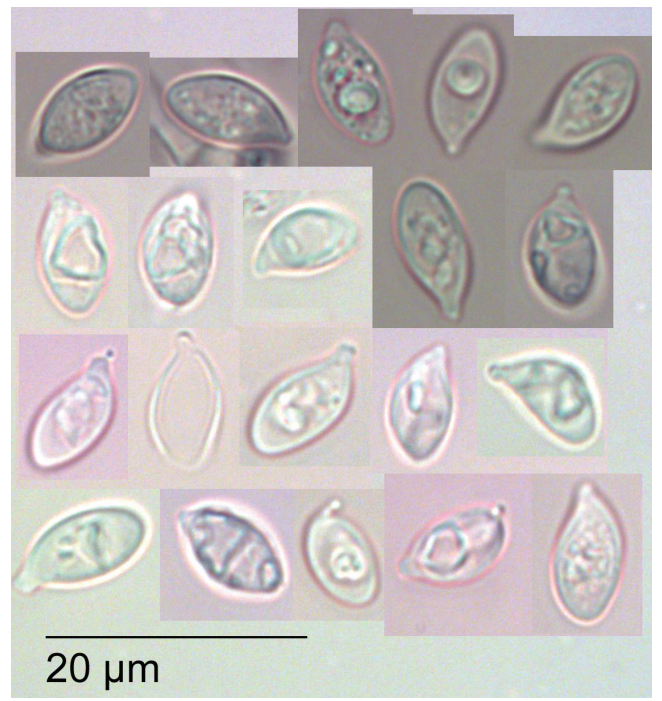

Figure 5. Gymnopus imbricatus Holotype PDD 95489. Spores (in $\mathrm{KOH}$ ).

towards base, always entirely smooth. Stipe base insititious and usually associated with a thin waxy to chalky cream layer of partially gelatinised hyphae covering the substrate, usually green with algal cells. Fruitbodies with garlic/rotten cabbage smell, especially when crushed.

Micromorphology. Pileipellis a partially gelatinised irregular clamped cutis of hyphae $4 \mu \mathrm{m}$ diameter, without intra or extracellular pigmentation, terminal layer with gelatinised coralloid elements, to $2 \mu \mathrm{m}$ wide, and occasional small finger-like trichodermal elements to $20 \mu \mathrm{m}$. Epidermal layer to $25 \mu \mathrm{m}$. Subepidermis of thick glassywalled non-gelatinised smooth hyaline hyphae, weakly dextrinoid. Basidia clavate to $50 \times 10 \mu \mathrm{m}$. Sterigmata to $5 \mu \mathrm{m}, 4$-spored. Basidioles to $50 \times 6 \mu \mathrm{m}$ cylindrical and tapered towards apex. Spores hyaline, lacrymoid $9.8 \pm 1.2 \times 5.1 \pm 0.4 \mu \mathrm{m}, \mathrm{Q}=1.9 \pm$ 0.3 including apiculus. Cheilocystidia and pleurocystidia not observed. Stipitipellis a cutis of parallel brown hyphae, to $6 \mu \mathrm{m}$ wide. Caulocystidia absent. 
Habitat. Forming imbricate colonies of dozens to hundreds of fruitbodies on bark and decorticate wood of dead branches and twigs, especially Kunzed and Leptospermum but occurs with other trees. Also occurs at the stem base of live trees.

Distribution. Broadly distributed and common in both North and South Islands of New Zealand.

Etymology. Imbricatus, pertaining to the often tiered and overlapping eccentrically stemmed caps.

Specimens examined. New Zealand, North Island: PDD 80766, on bark of Beilschmedia tawa, Erua Forest, Taupo, collector J.A. Cooper (JAC9329), 4 April, 2005. PDD 87398, bark on dead branch of Nothofagus, Waiohine Gorge, Wairarapa, Collector J.A. Cooper (JAC10310), 10 May 2007. PDD 87410, dead stems of Ripogonum scandens, Waiohine Gorge, Wairarapa, Collector J.A. Cooper (JAC10322), 10 May 2007.

New Zealand, South Island: PDD 101753, dead branches of Nothofagus menziesii, Riwaka Resurgence, Nelson, Collector P.L. Leonard (PL25404), 10 April, 2006. PDD 96141, dead twigs of Kunzea ericoides, Mt Fyffe Track, Kaikoura, collector J.A. Cooper (JAC11734), 26 Feb. 2011. PDD 80154, dead log of Nothofagus menziesii, Lewis Pass, Buller, collector J.A. Cooper (JAC8287), 24 November, 2001. PDD 80157, on dead de-corticate log, Lyell Walkway, Nelson, collector J.A. Cooper (JAC80157), 25 November, 2001. PDD 87675, living stem of Fuchsia excorticata, Saddle Hill, Mid Canterbury, Collector J.A. Cooper (JAC10495), 22 May 2005. Holotype PDD 95489 (Figs 4 and 5), base of live trees of Kunzea ericoides, Kennedy's Bush, Mid Canterbury, Collector J.A. Cooper (JAC11038), 24 May 2009. PDD 79799, bark of dead tree, Kennedy's Bush, Mid Canterbury, Collector J.A. Cooper (JAC8921), 20 March 2004. PDD 87186, on bark of living tree of Kunzea ericoides, Hinewai Reserve, Akaroa, Mid Canterbury, Collector J.A. Cooper (JAC10089), 3 June 2006. PDD 87660, fallen log, Racemans Track, Silverstream Valley, Dunedin, Collector S. Dodd (JAC10816), 13 May 2008. PDD 87659, on dead twigs of Kunzea ericoides, Evansdale Glen, Dunedin, Collector P.R. Johnston (JAC10815), 12 May 2008.

\section{Gymnopus hakaroa J.A. Cooper \& P. Leonard, sp. nov.}

http://species-id.net/wiki/Gymnopus_hakaroa

Holotype: PDD 87315. Registration identifier: IF550093

Diagnosis. G. hakaroa is distinguished from G. ceraceicola by smaller stature and a pruinose stipe lacking fascicles of agglutinate caulocystidia. It is distinguished from $\mathrm{G}$. imbricatus by non-imbricate growth, a consistently central stipe, and smaller basidiospores.

Macromorphology. Pileus 3-10 mm diam. convex, rusty tawny to umber, minutely felty, weakly radially furrowed and striate towards the margin. Lamella cream to yellow, waxy. Lamellae present, in series of three: intercalated short/long/short. Stipe central, cartilaginous, to $5 \times 0.6 \mathrm{~mm}$, equal, umber to black, paler towards base, smooth to minutely pruinose. Stipe base insititious and always associated with an obvious waxy to chalky cream layer of partially gelatinised hyphae covering the substrate, 


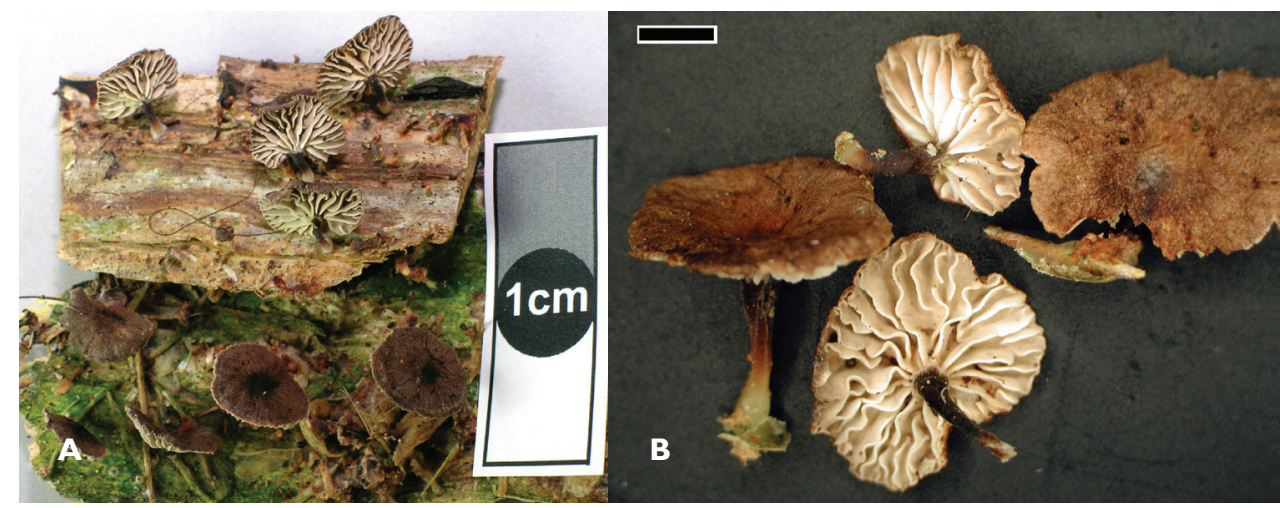

Figure 6. Gymnopus hakaroa A PDD 81086. Fruitbodies B scale $=2 \mathrm{~mm}$

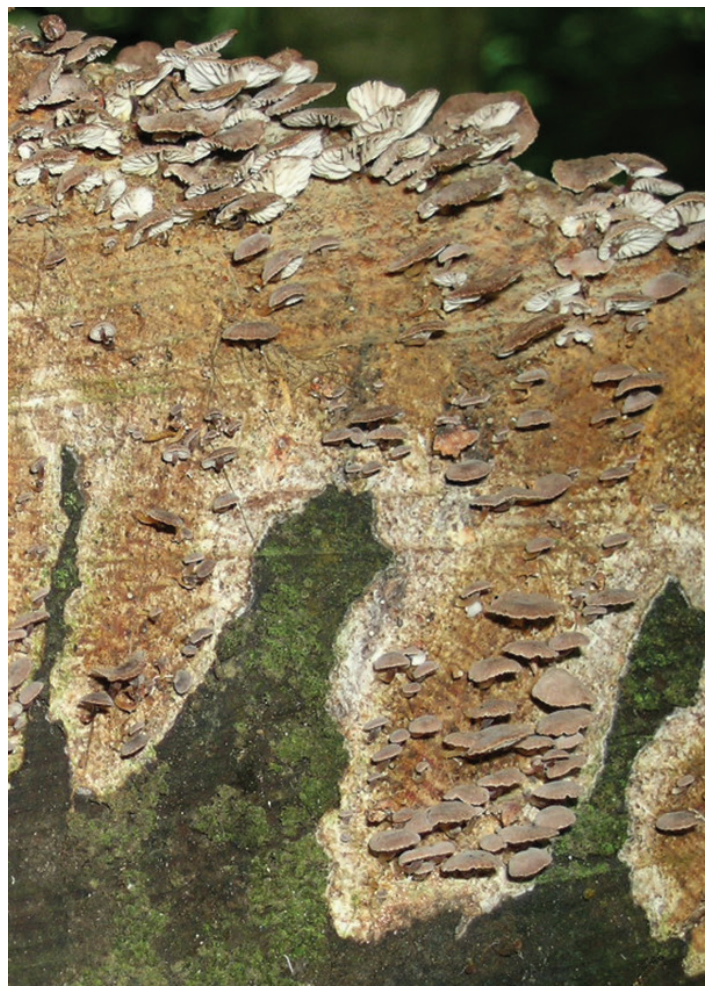

Figure 7. Gymnopus hakaroa Holotype PDD 87315. Fruitbodies, showing waxy substratum.

usually green with algal cells. Fruitbodies with garlic/rotten cabbage smell, especially when crushed.

Micromorphology. Pileipellis a partially gelatinised radially arranged clamped cutis of smooth hyphae to $3 \mu \mathrm{m}$ in diameter, with brown extra-cellular encrustation. Epidermal layer to $80 \mu \mathrm{m}$. Subepidermis of thick glassy-walled non-gelatinised smooth hyaline hyphae, to $3 \mu \mathrm{m}$ in diameter, weakly dextrinoid. Basidia clavate to $40 \times 8 \mu \mathrm{m}$. 


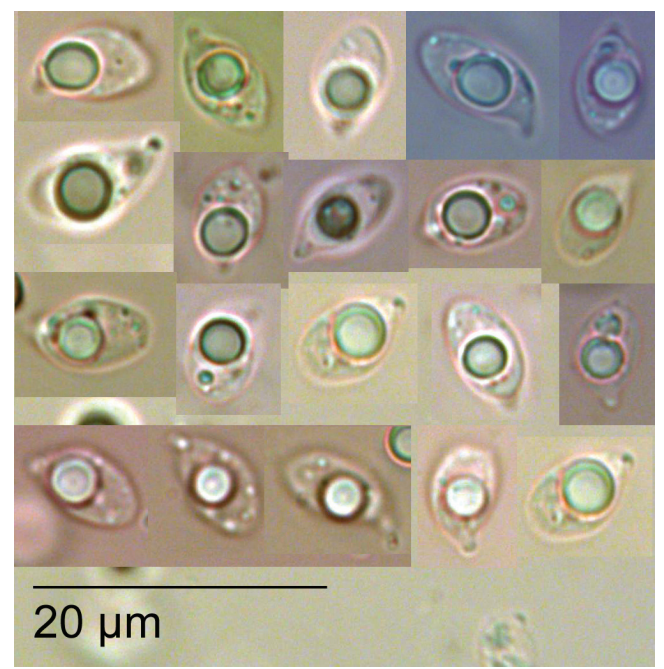

Figure 8. Gymnopus hakaroa Holotype PDD 87315. Spores (KOH).

Sterigmata to $7 \mu \mathrm{m}, 2-4$-spored. Basidioles cylindrical and tapered towards apex $40 \times$ $6 \mu \mathrm{m}$. Spores hyaline, lacrymoid $8.3 \pm 1 \times 4.8 \pm 0.3 \mu \mathrm{m}$, including apiculus, $\mathrm{Q}=1.7$ \pm 0.2 . Cheilocystidia and pleurocystidia not observed. Stipitipellis a cutis of hyaline to pale brown hyphae, to $5 \mu \mathrm{m}$ wide. Stipe without caulocystidia.

Habitat. Forming imbricate colonies of dozens to hundreds of fruitbodies on decorticate dead wood.

Distribution. Currently $G$. hakaroa is only known from a single location on the Canterbury Port Hills in the South Island of New Zealand.

Etymology. Hakaroa, a Maori name for the Bank's Peninsula region of New Zealand.

Notes. Sequence data (Fig 1) indicates a close phylogenetic relationship to G. imbricatus but there are consistent and substantial morphological differences.

Specimens examined. New Zealand, South Island: Holotype PDD 87315 (Figs 6 and 7) on dead log, Kennedys Bush Reserve, Port Hills, Mid Canterbury, Collector J.A. Cooper (JAC10225), 11 Feb. 2007. PDD 81086 (Fig. 8), on dead wood of Kunzea ericoides, Kennedys Bush Reserve, Port Hills, Mid Canterbury, Collector J.A. Cooper (JAC9585), 23 July, 2007. PDD 96390, on dead decorticate log of Melicytus ramiflorus, Kennedys Bush Reserve, Port Hills, Mid Canterbury, Collector J.A. Cooper (JAC11301), 17 April, 2010.

\section{Dicussion}

Gymnopus imbricatus, as its name suggests forms dense populations of small imbricate fruitbodies. It is most commonly associated with tea-tree (Kunzea ericoides and Leptospermum scoparium) and often found on the bark at the base of living trees. Gymnopus hakaroa is larger, with a dark minutely pruinose cap and again forms dense populations 


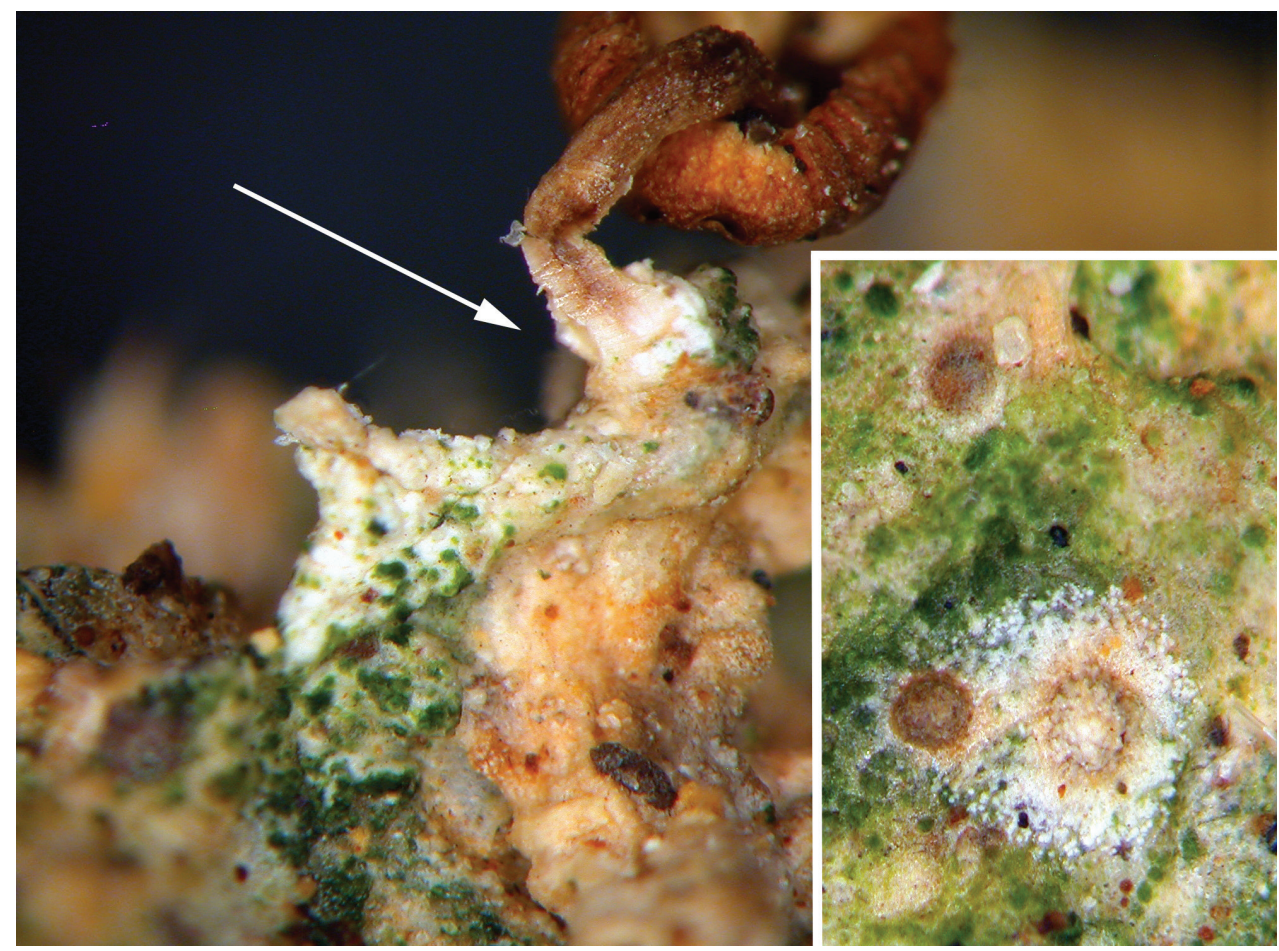

Figure 9. Gymnopus hakaroa PDD 96390. Stipe base (arrow) with surrounding algal mat. Inset, primordial arising from algal mat.

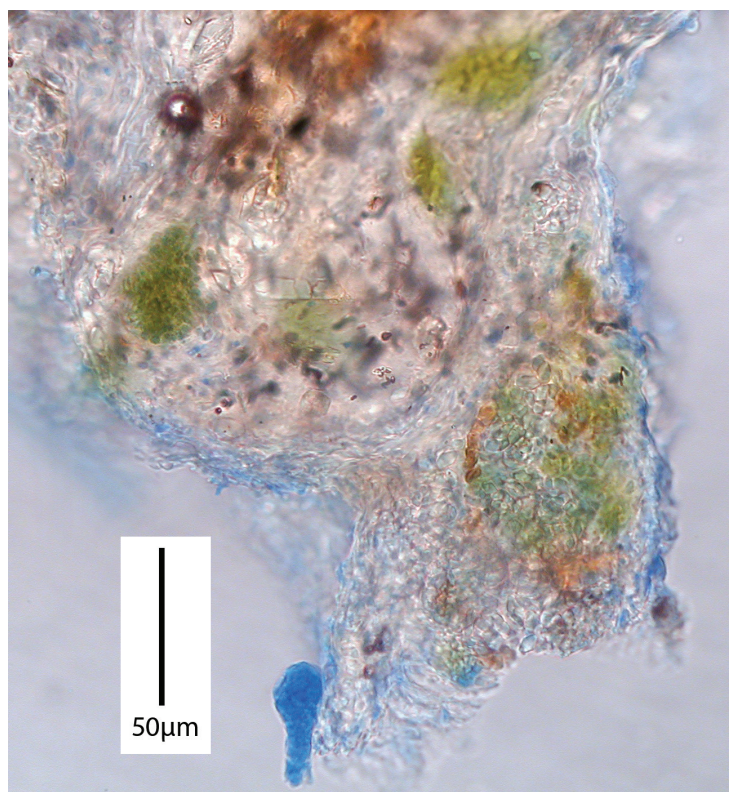

Figure 10. Gymnopus hakaroa PDD 96390. Pockets of algal cells embedded in hyphal tissue of stem base (cotton blue stain). 
on the bark of dead logs. These two species have smooth stems. Gymnopus ceraceicola is distinguished by larger fruitbodies, a pruinose stipe, and is more commonly associated with southern-beech forests on dead fallen logs. The species of Gymnopus described here belong in the /micromphale clade of Moncalvo et al. (2002) and share the diagnostic feature of this clade of a foetid odour likely due to the presence of mercaptan-like compounds. In New Zealand this feature is shared with Mycetinis curraniae (G. Stev.) J.A. Cooper \& P. Leonard, a marasmioid fungus distinguished by its ornamented hymeniderm pileipellis. Another very distinctive character common to all three Gymnopus species, and visible in the accompanying photographs (Figs 2 and 6), is the presence of a waxy layer of partially gelatinised hyphae on the substrate from which the fruitbodies emerge. This layer is usually green from the presence of embedded algal cells. Interestingly, some published images of $G$. foetidus in the northern hemisphere also show a similar layer, e.g. Antonín and Noordeloos (2010). Detailed examination of our material does show algal cells deeply embedded within the context of the waxy layer and the basal portion of the stipe (Figs 9 and 10), but it would seem unlikely that algal cells are present in sufficient numbers to confer any significant nutritional benefit to the fungus. The morphologically similar Marasmiellus affixus (Berk.) Singer, described from Australia and commonly known as the 'little stinker', is also associated with a waxy algae-infected layer. The association of $M$. affixus with alga was noted by Singer (1973) and has been speculated to be a basidio-lichen, although this has not proven (Lepp 2011). A partial, poor quality ITS1 sequence for $M$. affixus obtained during this work (not deposited) suggests it has affinity with Marasmiellus ramealis (Bull.) Singer rather than the taxa treated here.

\section{Acknowledgements}

Thanks to Dukchul Park, Landcare Research, for DNA extraction and sequencing, and to Sapphire McMullen-Fisher for material of Marasmiellus affixus. The New Zealand Department of Conservation is thanked for permission to collect specimens from reserves and national parks that they manage. The first author was supported through the Landcare Research Systematics Portfolio, with Core funding support from the Science and Innovation Group of the New Zealand Ministry of Business, Innovation and Employment.

\section{References}

Antonín V, Noordeloos ME (2010) A Monograph of Marasmioid and Collybioid fungi in Europe, IHW-Verlag.

Cooper JA, Leonard PL (2012) Boletopsis nothofagi sp. nov. associated with Nothofagus in the Southern Hemisphere. MycoKeys, 3: 13-22. doi: 10.3897/mycokeys.3.2762

Drummond AJ, Ashton B, Buxton S, Cheung M, Cooper A, Duran C, Field M, Heled J, Kearse M, Markowitz S, Moir R, Stones-Havas S, Sturrock S, Thierer T, Wilson A (2011) Geneious v5.4. Available from: http://www.geneious.com/ 
Glez-Peña D, Gómez-Blanco D, Reboiro-Jato M, Fdez-Riverola F, Posada D (2010) ALTER: program-oriented format conversion of DNA and protein alignments. Nucleic Acids Research 38(2): 14-18. doi: 10.1093/nar/gkq321

Hughes KW, Mather DA, Petersen RH (2010) A new genus to accommodate Gymnopus acervatus (Agaricales). Mycologia, 102: 1463-1478. doi: 10.3852/09-318

Katoh K, Misawa K, Kuma K, Miyata T (2002) MAFFT: a novel method for rapid multiple sequence alignment based on fast Fourier transform. Nucleic Acids Research 30: 30593066. doi: 10.1093/nar/gkf436

Lepp H (2011) Is Marasmiellus affixus a Lichen? Fungimap Newsletter 44: 14.

Mata JL, Hughes KW, Petersen RH (2004) Phylogenetic placement of Marasmiellus juniperinus. Mycoscience 45: 214-221. 10.1007/s10267-004-0170-3

Mata JL, Hughes KW, Petersen RH (2006) An investigation of /omphalotaceae (Fungi: Euagarics) with emphasis on the genus Gymnopus. Sydowia 53: 191-289.

Matheny PB, Curtis JC, Hofstetter V, Aime MC, Moncalvo J-M, Ge ZW, Yang ZL, Slot JC, Ammirati JF, Baroni TJ, Bougher NL, Hughes KW, Lodge DJ, Kerrigan RW, Seidl MT, Aanen DK, Dentis M, Danielle G, Desjardin DE, Kropp BR, Norvell LL, Parker A, Vellinga EC, Vilgalys R. Hibbett DS (2006) Major clades of Agaricales: a multi-locus phylogenetic overview. Mycologia, 98: 982-995. doi: 10.3852/mycologia.98.6.982

Milne I, Wright F, Rowe G, Marshal DF, Husmeier D and McGuire G (2004) TOPALi: Software for Automatic Identification of Recombinant Sequences within DNA Multiple Alignments. Bioinformatics 20(11): 1806-1807. doi: 10.1093/bioinformatics/bth155

Moncalvo JM, Vilgalys R, Redhead SA, Johnson JE, James TY, Aime MC, Hofstetter V, Verduin SJW, Larsson E, Baroni TJ, Thorn RG, Jacobsson S, Clémençon H, Miller OK (2002) One hundred and seventeen clades of euagarics. Molecular Phylogenetics and Evolution 23: 357-400. doi: 10.1016/S1055-7903(02)00027-1

Noordeloos ME (2012) Gymnopus (Pers.) Roussel. In Knudsen H, Vesterholt J (Eds) (2012) Funga Nordica, p. 341-349, Nordsvamp, Copenhagen.

Singer R (1973) A Monograph of the Neotropical Species of Marasmiellus. Beih. Nova Hedw. 44: 1-339.

Singer R (1986) Agaricales in modern taxonomy. $4^{\text {th }}$ Ed., Cramer, Koenigstein.

Stamatakis A (2006) RAxML-VI-HPC: Maximum Likelihood-based Phylogenetic Analyses with Thousands of Taxa and Mixed Models. Bioinformatics 22(21): 2688-2690. doi: 10.1093/bioinformatics/btl446

Wilson AW, Desjardin DE (2005) Phylogenetic relationships in the gymnopoid and marasmioid fungi (Basidiomycetes, euagarics clade). Mycologia 97: 667-679. doi: 10.3852/ mycologia.97.3.667 